\title{
EXPLAINING EXTREME EVENTS OF 2018 From a Climate Perspective
}
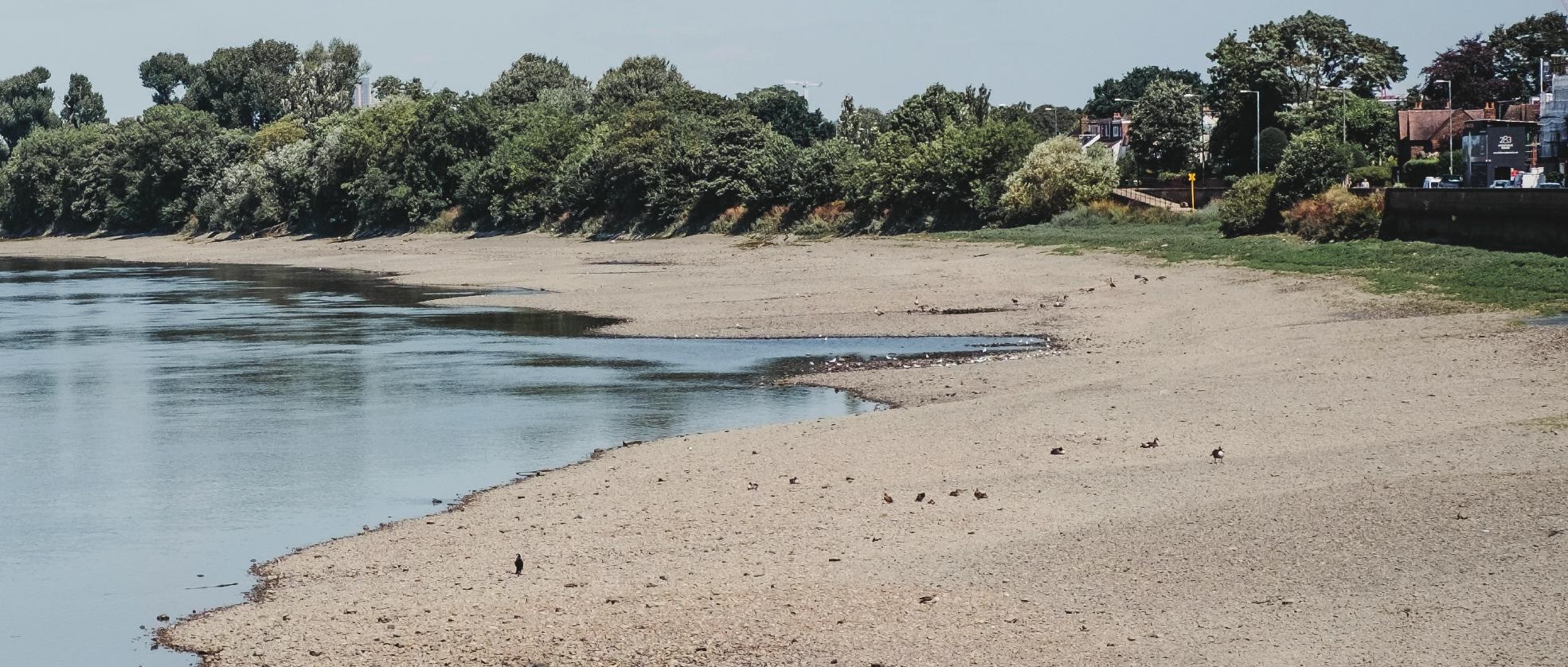

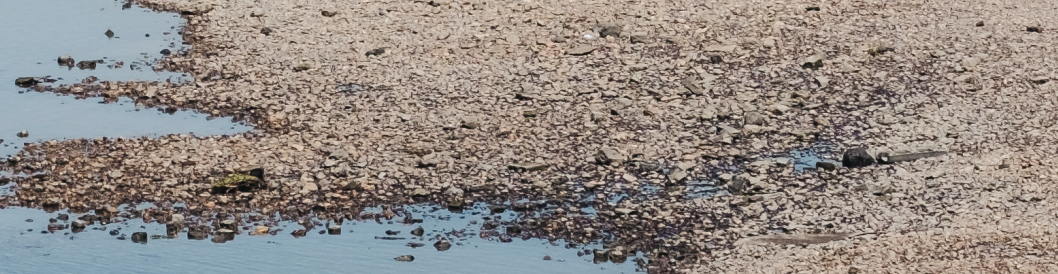

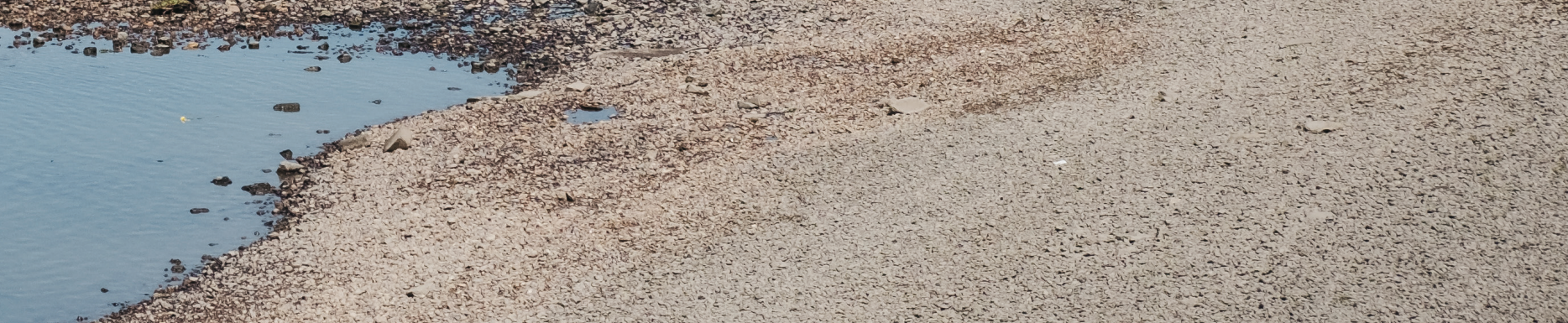

$x^{2}+m^{3}$

1.

Special Supplement to the Bulletin of the American Meteorological Society

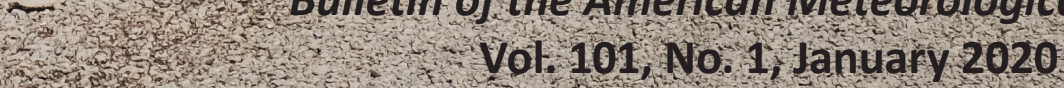




\title{
EXPLAINING EXTREME EVENTS OF 2018 FROM A CLIMATE PERSPECTIVE
}

\author{
Editors \\ Stephanie C. Herring, Nikolaos Christidis, Andrew Hoell, \\ Martin P. Hoerling, and Peter A. Stott
}

\section{BAMS Special Editors for Climate \\ Andrew King, Thomas Knutson, \\ John Nielsen-Gammon, and Friederike Otto}

Special Supplement to the

Bulletin of the American Meteorological Society

Vol. I0I, No. I, January 2020

American Meteorological Society 
CORRESPONDING EDITOR:

Stephanie C. Herring, PhD

NOAA National Centers for Environmental Information

325 Broadway, E/CC23, Rm IB-I3|

Boulder, CO, 80305-3328

E-mail: stephanie.herring@noaa.gov

Cover CReDit: iStock.com/Alena Kravchenko-River Thames receded during a heatwave in summer 2018 in London, United Kingdom.

\section{HOW TO CITE THIS DOCUMENT}

Citing the complete report:

Herring, S. C., N. Christidis, A. Hoell, M. P. Hoerling, and P. A. Stott, Eds., 2020: Explaining Extreme Events of 2018 from a Climate Perspective. Bull. Amer. Meteor. Soc., I0I (I), SI-SI28, doi:I0.II75/BAMS-ExplainingExtremeEvents20I8.I.

Citing a section (example):

Mahoney, K., 2020: Extreme Hail Storms and Climate Change: Foretelling the Future in Tiny, Turbulent Crystal Balls? [in "Explaining Extremes of 2018 from a Climate Perspective"]. Bull. Amer. Meteor. Soc., I0I (I), SI7-S22, doi:I0.II75/BAMSD-19-0233.I. 


\section{TABLE OF CONTENTS}

I. The Extreme 2018 Northern California Fire Season. . . . . . . . . . . . . . . . . . . I

2. Anthropogenic Impacts on the Exceptional Precipitation of 2018

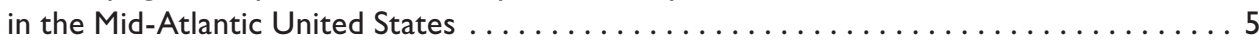

3. Quantifying Human-Induced Temperature Impacts on the 2018 United States Four Corners Hydrologic and Agro-Pastoral Drought . . . . . . . . . . . . . . I

4. Extreme Hail Storms and Climate Change: Foretelling the Future in Tiny, Turbulent Crystal Balls? . . . . . . . . . . . . . . . . . . . . . . . . . . . . . . . . . 17

5. The Extremely Cold Start of the Spring of 2018 in the United Kingdom . . . . . . . . . 23

6. The Exceptional Iberian Heatwave of Summer $2018 \ldots \ldots \ldots \ldots \ldots \ldots . \ldots . \ldots . \ldots 29$

7. Analyses of the Northern European Summer Heatwave of $2018 \ldots \ldots \ldots \ldots \ldots \ldots . \ldots 35$

8. Anthropogenic Influence on the 2018 Summer Warm Spell in Europe:

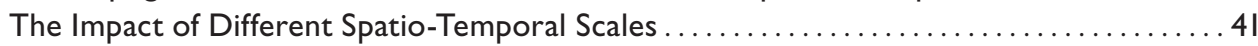

9. On High Precipitation in Mozambique, Zimbabwe and Zambia in February 2018 . . . . . 47

10. The Record Low Bering Sea Ice Extent in 2018: Context, Impacts, and an Assessment of the Role of Anthropogenic Climate Change ............. 53

II. The Late Spring Drought of 2018 in South China...................... 59

12. Anthropogenic Influence on 2018 Summer Persistent Heavy Rainfall

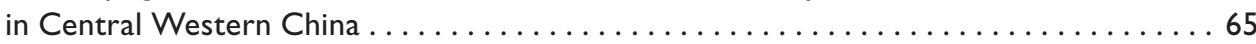

13. Conditional Attribution of the 2018 Summer Extreme Heat over Northeast China: Roles of Urbanization, Global Warming, and Warming-Induced Circulation Changes .... . 7I

14. Effects of Anthropogenic Forcing and Natural Variability on the 2018 Heatwave in Northeast Asia. . . . . . . . . . . . . . . . . . . . 77

15. Anthropogenic Influences on the Persistent Night-Time Heat Wave in Summer 2018 over Northeast China . . . . . . . . . . . . . . . . . . . . . . 83

16. Anthropogenic Contributions to the 2018 Extreme Flooding over the Upper Yellow River Basin in China . . . . . . . . . . . . . . . . . . . . . . . . . . 89

17. Attribution of the Record-Breaking Consecutive Dry Days in Winter 2017/18

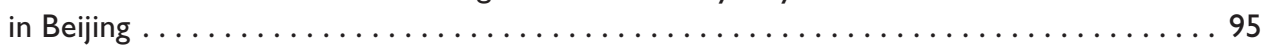

18. Quantifying Human Impact on the 2018 Summer Longest Heat Wave

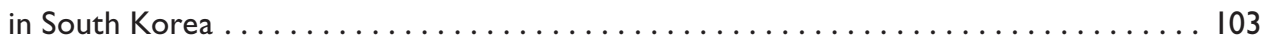

19. The Heavy Rain Event of July 2018 in Japan Enhanced by Historical Warming. . . . . . . 109

20. Deconstructing Factors Contributing to the 2018 Fire Weather in Queensland, Australia ...................................

21. A I-Day Extreme Rainfall Event in Tasmania: Process Evaluation and Long Tail Attribution 


\author{
Jonathan M. Winter, Huanping Huang, Erich C. Osterberg, and Justin S. Mankin
}
Exceptional January-September total precipitation contributed to flooding across the mid-Atlantic United States from May to September 2018, and was made
I.I to 2.3 times more likely by anthropogenic climate change.

\begin{abstract}
$\mathrm{F}$ lash flooding surged through the old district of Ellicott City, Maryland, on 27 May 2018, turning Main Street into whitewater rapids, upending cars, destroying businesses, and leading to one death (Campbell and Rentz 2018). As of May 2019, damage from the Ellicott City flood had cost $\$ 12$ million, and the city was considering flood mitigation plans that ranged from $\$ 63$ to $\$ 175$ million (Logan 2019). Ellicott City was just one of 12 significant heavy precipitation and flooding events that occurred between May and September of 2018, shattering precipitation records across the region (National Weather Service 2019). Other notable events included 3 June, when eight West Virginia counties declared states of emergency after intense precipitation flooded bridges and washed out roads (Maher 2018), and 21-24 July, when historic rainfall across the Washington, D.C., Metropolitan Area and northern Baltimore County in Maryland resulted in more than a dozen highwater rescues of motorists stranded by flash flooding (Halverson and Samenow 2018). These exceptional heavy rainfall events are consistent with expectations from global warming (Pendergrass 2018) and
\end{abstract}

AFFILIATIONS: WINTER AND MANKIN-Department of Geography, and Department of Earth Sciences, Dartmouth College, Hanover, New Hampshire; and HUANG AND OsterberG-Department of Earth Sciences, Dartmouth College, Hanover, New Hampshire CORRESPONDING AUTHOR: Jonathan M. Winter,

jonathan.m.winter@dartmouth.edu

DOI:10.1175/BAMS-D-19-0172.I

A supplement to this article is available online (I0.II75/BAMS-

D-19-0172.2)

(c) 2020 American Meteorological Society

For information regarding reuse of this content and general copyright

information, consult the AMS Copyright Policy. observed increases in extreme precipitation across the broader northeastern United States (Huang et al. 2017; Hoerling et al. 2016; Frei et al. 2015).

We examine the mid-Atlantic states of Pennsylvania, New Jersey, Maryland, Washington, D.C., Delaware, and West Virginia, which all experienced remarkable total and extreme (99th percentile wet days) precipitation in 2018 that contributed to flooding. For the years 1920-2018, 2018 has the highest or one of the three highest January-September total precipitation amounts at $33 \%$ and $62 \%$ of stations (Fig. 1a), respectively, and the highest or one of the three highest May-September extreme precipitation amounts at $6 \%$ and $13 \%$, respectively (Fig. 1b). Spatially averaged, 2018 has the highest total precipitation on record (1-in-99 year event), while extreme precipitation is the fourth highest (4-in-99 year event), shown in Figs. 1c and 1d. Here, we assess the fraction of 2018 total and extreme precipitation risk attributable to anthropogenic forcing using station observations and a large ensemble of climate simulations.

DATA AND METHODS. Station observations are from the Global Historical Climatology NetworkDaily (GHCN-D) dataset (Menne et al. 2012a,b). Our analysis is conducted using the 63 stations in our domain with daily observations that are at least $80 \%$ complete for 1920-2018 and 2018 (Fig. 1a). We treat any years less than $80 \%$ complete as missing. We choose 1920 as the start date of our analysis to balance spatial and temporal coverage of station data as well as to maximize overlap with climate simulations. We use gridded area averaging following Huang et al. (2017).

To assess the contribution of anthropogenic climate change to the exceptional precipitation of 2018, we use the historical climate simulations from version 1 of the Community Earth System Model (CESM1) under the Large Ensemble Project (LENS) from the 

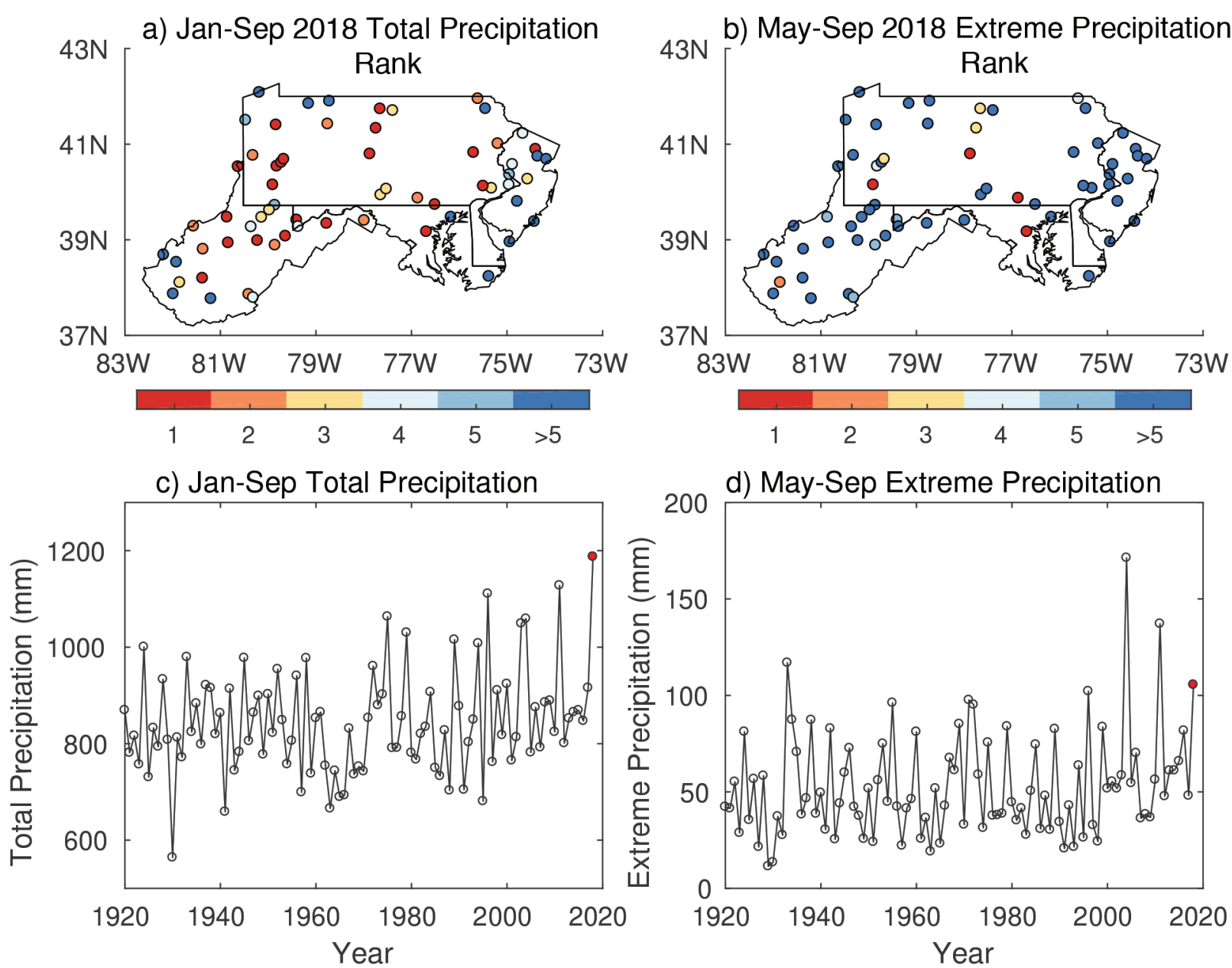

FIG. I. GHCN-D (a) January to September 2018 total precipitation rank and (b) May to September 2018 extreme precipitation rank by station for 1920-2018. Regionally averaged time series of GHCN-D (c) January to September total precipitation and (d) May through September extreme precipitation. Red dots highlight 2018 precipitation.

National Center of Atmospheric Research (Kay et al. 2015). LENS uses CESM1 at $\sim 1^{\circ} \times 1^{\circ}$ spatial resolution to create a single model large ensemble where each run is initialized with a small roundoff error $\left(10^{-14} \mathrm{~K}\right)$ in the atmospheric temperature fields (Kay et al. 2015). As such, each ensemble member is a plausible trajectory of historical climate due to the model's representation of forced and unforced variability, and together the 40 ensemble members provide a much larger range of outcomes from internal variability than either observations or any one model run can provide. We combine historical (1920-2005) and future climate simulations (2006-18) forced with RCP 8.5 to create forty 99-yr transient simulations from 1920 to 2018.

We consider two precipitation metrics that contributed to the extensive mid-Atlantic flooding of 2018. The first is May through September extreme precipitation (hereafter extreme precipitation). We define extreme precipitation as the sum of precipitation falling on the top $1 \%$ of wet days (99th percentile wet days) from 1 May to 30 September, because the flooding of interest occurred during those months. The second metric is January through September precipitation (hereafter total precipitation). We define total precipitation as the sum of precipitation 1 January to 30 September, and use it as a proxy for antecedent soil moisture because flooding can be exacerbated by high antecedent soil moisture (Collins 2019; Lapenta et al. 1995). To determine the 99 th percentile wet day threshold, we use all wet days (defined as days with precipitation $\geq 1 \mathrm{~mm}$ in all 12 months) ranked from highest to lowest. GHCN-D thresholds are calculated by station from 1920-2018, and LENS thresholds are calculated by grid cell from 1920 to 2018 . We determine the rank of 2018 for regionally averaged total and extreme precipitation from GHCN-D over 
the 99-yr record (Fig. 1). From each LENS historical ensemble member time series of total precipitation, we first remove the time-evolving ensemble mean, which represents the externally forced response common to all simulations (Maher et al. 2019), creating anomalies. Then, we add the climatological ensemble mean magnitude of total precipitation from the early part of the record (1920-50) to the anomalies. We repeat the process for extreme precipitation. This creates a 40-member ensemble of regional total and extreme precipitation for 1920-2018 in a counterfactual world without late twentieth century (1951-2018) forcing (hereafter historical reduced forcing). Results are insensitive to the time period used to calculate climatological ensemble mean magnitudes (not shown). We choose to modify LENS historical data as our counterfactual because while CESM1 reasonably captures mid-Atlantic precipitation (Fig. S1), the LENS preindustrial data are substantially wetter than the LENS historical data (not shown), which is inconsistent with paleoclimate data (Ljungqvist et al. 2016).

Using elements of Diffenbaugh et al. (2017), we assess the fraction attributable risk (FAR; Allen 2003; Stott et al. 2016) to anthropogenic climate change by 1) finding the magnitude of total precipitation with the same rank as 2018 in the GHCN-D observations (hereafter similar to 2018) in each of the 40 LENS historical reduced forcing 99-yr time series; 2) averaging those 40 magnitudes to calculate a threshold defining LENS historical reduced forcing total precipitation similar to 2018 ; 3 ) using that mean to calculate the probability of total precipitation similar to 2018 in the 40 LENS historical and historical reduced forcing 99-yr time series; and 4) calculating FAR as

$$
\mathrm{FAR}=1-\frac{P_{0}}{P_{1}}
$$

where $P_{0}$ is the probability of exceeding the threshold of precipitation similar to 2018 in the LENS histori- cal time series conditional on the presence of natural and early twentieth-century anthropogenic forcings (historical reduced forcing), and $P_{1}$ is the probability of exceeding the threshold of precipitation similar to 2018 in the LENS historical time series conditional on the presence of natural and full twentieth-century anthropogenic forcings (historical), and $P_{1} / P_{0}$ is the risk ratio (RR). We then calculate FAR for extreme precipitation similar to 2018, and the combined occurrence of total precipitation and extreme precipitation similar to 2018, using the same methodology. We calculate uncertainty around FAR and RR by bootstrapping (Efron and Tibshirani 1986) the 40 ensemble members from the LENS historical data 1,000 times, repeating the analysis above, and determining 95\% confidence intervals (CI) using the bootstrap standard error estimate of Paciorek et al. (2018).

RESULTS. LENS reasonably simulates regionally averaged GHCN-D total precipitation [see Fig. Sla in the online supplemental material; $p=0.29$, KolmogorovSmirnov (K-S) test], but not extreme precipitation (Fig. S1b; $p<0.001$, K-S test). Figure 2 shows the probability and cumulative probability of total precipitation and extreme precipitation similar to 2018 from the LENS historical and historical reduced forcing simulations. These figures indicate that the historical simulations have larger total and extreme precipitation than the historical reduced forcing simulations.

Table 1 shows the fraction of risk attributable to anthropogenic climate change for total and extreme precipitation similar to 2018. The 1-in-99 year total precipitation and 4-in-99 year extreme precipitation mean magnitudes from the historical reduced forcing data are $1070.1 \mathrm{~mm}$ and $52.7 \mathrm{~mm}$, respectively. In LENS, the late-twentieth-century anthropogenic forcing is responsible for 35\% of 1-in-99 year January to September total precipitation occurrences, and a 1.5 times increase in the likelihood of total precipita-

TABLE I. LENS historical reduced forcing (HIST-RF) and historical (HIST) probability of mid-Atlantic total and extreme precipitation similar to 2018 , and the resulting risk ratio (RR) and fraction attributable risk (FAR).

\begin{tabular}{|l|c|c|c|c|}
\hline \multicolumn{1}{|c|}{ Precipitation condition } & HIST-RF $\left(\boldsymbol{P}_{0}\right)$ & HIST $\left(\boldsymbol{P}_{\mathbf{I}}\right)$ & $\mathbf{R R}(\mathbf{9 5} \% \mathbf{C I})$ & FAR (95\% CI) \\
\hline Total Jan-Sep & $0.68 \%$ & $1.04 \%$ & $1.53(1.09,2.25)$ & $0.35(0.17,0.59)$ \\
\hline Extreme May-Sep & $3.69 \%$ & $4.14 \%$ & $1.12(1.05,1.21)$ & $0.11(0.05,0.18)$ \\
\hline Total Jan-Sep and extreme May-Sep & $0.15 \%$ & $0.23 \%$ & $1.53(0.85,4.65)$ & $0.35(-0.15,0.82)$ \\
\hline
\end{tabular}



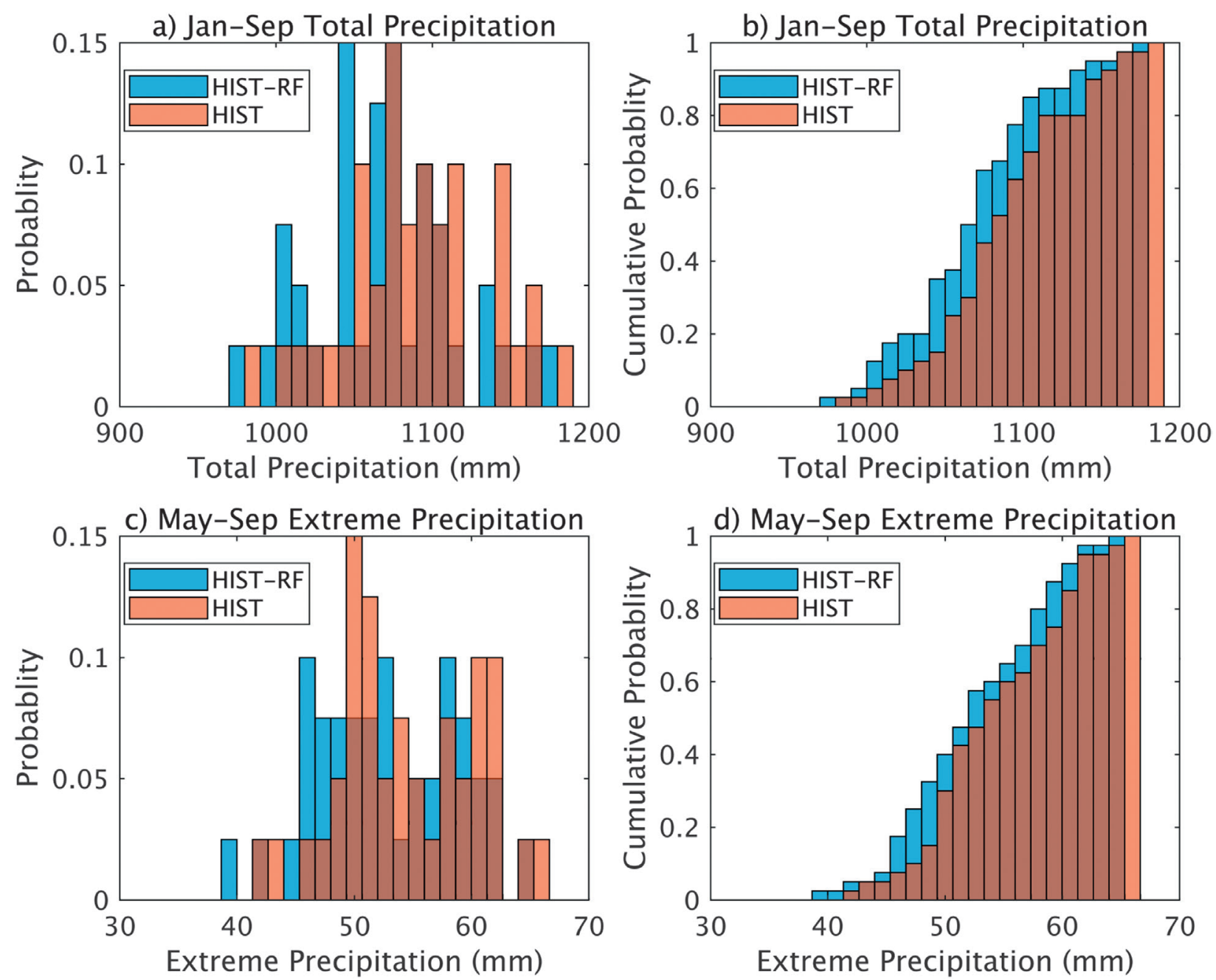

FIG. 2. LENS historical (HIST) and historical reduced forcing (HIST-RF) (a) I-in-99 year January to September total precipitation probability, (b) I-in-99 year January to September total precipitation cumulative probability, (c) 4-in-99 year May to September extreme precipitation probability, and (d) 4-in-99 year May to September extreme precipitation cumulative probability.

tion similar to 2018 . In addition, $11 \%$ of 4 -in-99 year May to September extreme precipitation occurrences are attributable to the LENS late-twentieth-century anthropogenic forcing. We find no statistically significant influence of late-twentieth-century anthropogenic forcing on combined 1-in-99 year January to September total precipitation and 4-in-99 year May to September extreme precipitation occurrences. Extreme precipitation FAR should be interpreted with caution given the limitations of LENS historical simulations in accurately representing extreme precipitation when compared to GHCN-D observations (Fig. S1b). We evaluated the sensitivity of our findings to methodology, and find qualitatively similar, but larger, responses to anthropogenic forcing (see the online supplemental material).
CONCLUSIONS. The mid-Atlantic region was impacted by damaging floods throughout the warm season of 2018 (National Weather Service 2019). These floods were associated with the highest total precipitation from January to September and the fourth highest extreme precipitation from May to September for 1920-2018. Contrasting LENS historical and LENS historical reduced forcing, we find that anthropogenic climate change increased the probability of total precipitation associated with the exceptional flooding of 2018 by 1.1 to 2.3 times. Incorporating additional large ensembles, especially from models that better reproduce observed extreme precipitation in the mid-Atlantic, as well as partitioning greenhouse gas and aerosol anthropogenic forcings, would strengthen this attribution. 
ACKNOWLEDGMENTS. This work was supported by the Vermont Established Program for Stimulating Competitive Research (NSF Award OIA 1556770). GHCN$\mathrm{D}$ data were provided by NOAA NCEI. LENS data were provided by the National Center for Atmospheric Research CESM Large Ensemble Community Project, with supercomputing resources provided by NSF/CISL/Yellowstone and the University of Toronto, and archiving provided by the Earth System Grid (www.earthsystemgrid.org). We thank Dartmouth Research Computing for their help and administration of the Discovery Cluster.

\section{REFERENCES}

Allen, M., 2003: Liability for climate change. Nature, 421, 891-892, https://doi.org/10.1038/421891a.

Campbell, C., and C. Rentz, 2018: How Ellicott City flooded: A timeline. Baltimore Sun, 1 June, https:// www.baltimoresun.com/weather/bs-md-ellicottcity-flooding-timeline-20180530-story.html.

Collins, M. J., 2019: River flood seasonality in the Northeast United States: Characterization and trends. Hydrol. Processes, 33, 687-698, https://doi. org/10.1002/hyp.13355.

Diffenbaugh, N. S., and Coauthors, 2017: Quantifying the influence of global warming on unprecedented extreme climate events. Proc. Natl. Acad. Sci. USA, 114, 4881-4886, https://doi.org/10.1073/pnas.1618082114.

Efron, B., and R. Tibshirani, 1986: Bootstrap methods for standard errors, confidence intervals, and other measures of statistical accuracy. Stat. Sci., 1, 54-75, https://doi.org/10.1214/ss/1177013815.

Frei, A., K. E. Kunkel, and A. Matonse, 2015: The seasonal nature of extreme hydrological events in the northeastern United States. J. Hydrometeor., 16, 2065-2085, https://doi.org/10.1175/JHM-D-14-0237.1.

Halverson, J., and J. Samenow, 2018: Here's how Saturday's storm unleashed a historic July deluge in Washington. Washington Post, 22 July, https:// www.washingtonpost.com/news/capital-weathergang/wp/2018/07/22/heres-how-saturdays-stormunleashed-a-historic-july-deluge-in-washington/.

Hoerling, M., J. Eischeid, J. Perlwitz, X.-W. Quan, K. Wolter, and L. Cheng, 2016: Characterizing recent trends in U.S. heavy precipitation. J. Climate, 29, 2313-2332, https://doi.org/10.1175/JCLI-D-15-0441.1.

Huang, H., J. M. Winter, E. C. Osterberg, R. M. Horton, and B. Beckage, 2017: Total and extreme precipitation changes over the northeastern United States. J. Hydrometeor., 18, 1783-1798, https://doi.org/10.1175/ JHM-D-16-0195.1.

Kay, J. E., and Coauthors, 2015: The Community Earth System Model (CESM) Large Ensemble Project: A community resource for studying climate change in the presence of internal climate variability. Bull. Amer. Meteor. Soc., 96, 1333-1349, https://doi. org/10.1175/BAMS-D-13-00255.1.

Lapenta, K. D., and Coauthors, 1995: The challenge of forecasting heavy rain and flooding throughout the eastern region of the National Weather Service. Part I: Characteristics and events. Wea. Forecasting, 10, 78-90, https://doi.org/10.1175/15200434(1995)010<0078:TCOFHR>2.0.CO;2.

Ljungqvist, F. C., P. J. Krusic, H. S. Sundqvist, E. Zorita, G. Brattström, and D. Frank, 2016: Northern Hemisphere hydroclimate variability over the past twelve centuries. Nature, 532, 94-98, https://doi. org/10.1038/nature17418.

Logan, E., 2019: Howard to bore a tunnel and raze four buildings to ease Ellicott City flooding, could cost \$140 million. Baltimore Sun, 13 May, https://www. baltimoresun.com/maryland/howard/ph-ho-cfflood-plan-20190513-story.html.

Maher, K., 2018: Flood warnings in effect in parts of West Virginia, Maryland and Virginia. Wall Street Journal, 4 June, https://www.wsj.com/articles/ flood-warnings-in-effect-in-parts-of-west-virginiamaryland-and-virginia-1528135632.

Maher, N., and Coauthors, 2019: The Max Planck Institute Grand Ensemble: Enabling the exploration of climate system variability. J. Adv. Model. Earth Syst., 11, 2050-2069, https://doi.org/10.1029/2019MS001639.

Menne, M. J., and Coauthors, 2012a: Global historical climatology network-daily (GHCN-daily), version 3.22. NOAA National Climatic Data Center, accessed 1 May 2019, https://doi.org/10.7289/V5D21VHZ.

Menne, M. J., I. Durre, R. S. Vose, B. E. Gleason, and T. G. Houston, 2012b: An overview of the Global Historical Climatology Network-Daily Database. J. Atmos. Oceanic Technol., 29, 897-910, https://doi. org/10.1175/JTECH-D-11-00103.1.

National Weather Service, 2019: Record rain and flooding of 2018. NWS, accessed 1 May 2019, https://www. weather.gov/lwx/2018floods.

Paciorek, C. J., D. A. Stone, and M. F. Wehner, 2018: Quantifying statistical uncertainty in the attribution of human influence on severe weather. Wea. Climate Extremes, 20, 69-80, https://doi.org/10.1016/j. wace.2018.01.002.

Pendergrass, A. G., 2018: What precipitation is extreme? Science, 360, 1072-1073, https://doi.org/10.1126/science.aat 1871.

Stott, P. A., and Coauthors, 2016: Attribution of extreme weather and climate-related events. Wiley Interdiscip. Rev.: Climate Change, 7, 23-41, https:// doi.org/10.1002/wcc.380. 
